Report No. BMI-1332

UC-25 Metallurgy and Ceramics (TID-4500, 14th Ed.)

Contract No. W-7405-eng-92

REACTIONS IN T HE NIOBIUM-HYDROGEN SYSTEM

by

William M. Albrecht

W. Douglas Goode, Jr.

Manley W. Mallett

April 1, 1959

BATTELLE MEMORIAL INST ITUTE

505 King Avenue

Columbus 1, Ohio 


\section{DISCLAIMER}

This report was prepared as an account of work sponsored by an agency of the United States Government. Neither the United States Government nor any agency Thereof, nor any of their employees, makes any warranty, express or implied, or assumes any legal liability or responsibility for the accuracy, completeness, or usefulness of any information, apparatus, product, or process disclosed, or represents that its use would not infringe privately owned rights. Reference herein to any specific commercial product, process, or service by trade name, trademark, manufacturer, or otherwise does not necessarily constitute or imply its endorsement, recommendation, or favoring by the United States Government or any agency thereof. The views and opinions of authors expressed herein do not necessarily state or reflect those of the United States Government or any agency thereof. 


\section{DISCLAIMER}

Portions of this document may be illegible in electronic image products. Images are produced from the best available original document. 
Page

ABSTRACT .............................. 1

INT RODUCTION .................................. 1

MATERIAL . . . . . . . . . . . . . . . . . . . 2

EXPERIMENT AL METHODS . . . . . . . . . . . . . . . 2

RESULTS AND DISCUSSIONS ...................... . 3

Equilibria ... . . . . . . . . . . . . . . . . . 3

Sorption Kinetics and Diffusion.

CONCLUSIONS ....................... . . 18

ACKNOWLEDGMENT . . . . . . . . . . . . . . . . . 18

REFERENCES............................. 18 


\title{
REACTIONS IN THE NIOBIUM-HYDROGEN SYSTEM
}

\author{
William M. Albrecht, W. Douglas Goode, Jr., and Manley W. Mallett
}

Equilibria in the niobium-hydrogen system were determined in the range 100 to $900 \mathrm{C}, 0.1$ to $1000 \mathrm{~mm}$ of mercury hydrogen pressure, and hydrogen/niobium atomic ratios of 0.01 to 0.85 . X-ray measurements were obtained at 25 to $400 \mathrm{C}$ at hydrogen/niobium ratios up to 0.54 .

The studies showed that a solid solution of hydrogen in niobium is produced throughout most of the system. A miscibility gap u'as found at low temperatures and pressures, with a critical point at about a temperature of $140 \mathrm{C}$, a hydrogen pressure of $0.01 \mathrm{~mm}$ of mercury, and a hydrogen/niobium ratio of 0.3 . Sorption rates at 300 to $550 \mathrm{C}$ were initially linear. At higher temperatures, sorption rates were controlled by diffusion in the metal matrix. Diffusion coefficients at 600 to $700 \mathrm{C}$ can be expressed by

$$
D=0.0215 \exp [(-9370 \pm 600): R T 1
$$

Desorption rates were lower than those predicted by diffusion.

\section{INTRODUCTION}

In a previous study (1) the equilibria in the niobium-hydrogen system were investigated in the ranges 100 to $900 \mathrm{C}, 10$ to $1000 \mathrm{~mm}$ of mercury hydrogen pressure, and at hydrogen/niobium atomic ratios of 0.01 to 0.85 . A single-phase solid solution was produced throughout most of the system. However, the presence of a two-phase region in the system was indicated at low temperatures and hydrogen pressures. The present study was made to establish more definitely the extent of this region. Using a more sensitive apparatus equilibria were established at pressures lower than those of the preceding work. Equilibrium products were identified by X-ray diffraction. Also, studies were made of the kinetics of the reaction of hydrogen with niobium and of the diffusion of hydrogen in the metal.

Paxton and Sheehan (2) measured the solubility of hydrogen in niobium at a pressure of 1 atm to establish partially the phase diagram of the system. They also made permeability experiments to measure the rate of diffusion of hydrogen in the metal. Gulbransen and Andrew (3) have reported the kinetics of the reaction of hydrogen with niobium for 200 to $900 \mathrm{C}$ at hydrogen pressures up to $57 \mathrm{~mm}$ of mercury. Both of these studies have a bearing on the present investigation.

(1) References at end of report. 
MATERIAL

The original niobium bars were cut and fabricated to approximately $0,3-, 0,6-$, and $0.9 \mathrm{~cm}$ rods and to $0.03 \mathrm{~cm}$ sheet. Samples for the reaction-rate and diffusion studies were vacuum annealed at $1150 \mathrm{C}$ for $1 / 2 \mathrm{hr}$. The analysis of the fabricated niobium after annealing is shown in Table 1. The niobium had a Vickers hardness of 113.

TABLE 1. ANALYSIS OE THE NIOBIUM FOR REACTION-RATE AND DIFEUSION ST UDIES AFTER FABRICATION AND ANNEALING

\begin{tabular}{lc}
\hline \multicolumn{1}{c}{ Element } & Analysis, $\mathrm{ppm}$ by weight \\
\hline Tantalum & 1500 \\
Iron & 200 \\
Tin & 200 \\
Molybdenum & 50 \\
Silicon & 50 \\
Vanadium & 50 \\
Chromium & 20 \\
Aluminum & 20 \\
Titanium & 20 \\
Carbon & 120 \\
Oxygen & 430 \\
Nitrogen & 120 \\
Hydrogen & $<3(\mathrm{a})$ \\
\hline \hline
\end{tabular}

(a) After degassing.

Pure hydrogen was obtained from the the rmal decomposition of uranium hydride prepared from dry tank hydrogen and degassed uranium chips.

\section{EXPERIMENTAL METHODS}

The method to obtain equilibrium data has been described. (1) However, for this work, the micro-Sieverts apparatus was equipped with a differential oil manometer to measure pressures in the range 0.1 to $50 \mathrm{~mm}$ of mercury. Briefly, data were obtained as follows. A measured amount of hydrogen was added to the calibrated reaction tube containing 3 to $4 \mathrm{~g}$ of sheet $(0.03 \mathrm{~cm}$ thick) niobium. At the desired temperature, the system was allowed to come to constant (equilibrium) pressure as measured on the differential oil manometer. The equilibrium composition was calculated from the equilibrium pressure, specimen weight, volume of gas addition, and volume capacity of the reaction system at the experimental temperature.

Sorption rates were measured with another modified Sieverts apparatus. (4) Essentially, the apparatus consists of a reaction tube, pressure regulator, gas buret, and a high-vacuum-pumping system. Cylindrical specimens approximately $0.3,0.6$, and $0.9 \mathrm{~cm}$ in diameter and 1 to $3 \mathrm{~cm}$ long were dry-abraded through $240-, 400 \mathrm{~m}$, and 600-grit silicon carbide paper. Each specimen was weighed, measured, and spot welded to a platinum platinum-10 w/o rhodium thermocouple. After a light final polish with dry 600-grit silicon carbide paper, the sample was hung in the reaction tube and 
sealed to the Sieverts apparatus. The system was evacuated to less than $0.01 \mu$ of mercury, and then heated to the temperature of the run.

The reaction was initiated by admitting hydrogen through the pressure regulator to the reaction tube. The buret was kept balanced at atmospheric pressure at all times. Readings of the buret were taken at convenient time intervals, depending upon the speed of the reaction. The amount of gas reacted with the sample was the difference between the volume added from the buret and the volume remaining in the gas phase in the calibrated dead space of the reaction tube.

Diffusion coefficients for hydrogen in niobium were determined from sorption-rate data. A few experiments were made to determine diffusion rates by a technique based on measuring rates of outgassing of specimens in a vacuum of $10^{-6}$ to $10^{-5} \mathrm{~mm}$ of mercury at various temperatures. The apparatus and procedure have been described previously. $(5,6)$ The rates of hydrogen outgassing were measured for $0.6-\mathrm{cm}$ diameter niobium cylinders with initial hydrogen/niobium ratios of 0.03 to 0.06 .

\section{RESULTS AND DISCUSSIONS}

\section{Equilibria}

The equilibrium data obtained in the present study have been combined with those previously reported for the niobium-hydrogen system to give comprehensive coverage of the ranges 100 to $900 \mathrm{C}, 0.1$ to $1000 \mathrm{~mm}$ of mercury pressure, and 0.01 to 0.85 hydrogen/niobium ratios. Figure 1 is a logarithmic plot of equilibrium pressure against composition for various temperatures. It is seen that none of the isotherms shows invariant pressures. This indicates that there is no two-phase region within these ranges. Equilibrium data could not be obtained at lower temperatures and pressures because of the extremely long times required.

The equilibria in the niobium-hydrogen system were interpreted in terms of the conditions required to form various products (solid solutions) having definite hydrogen/ niobium ratios. For a given ratio or composition, the equilibria can be expressed by the equation,

$$
\log P_{\mathrm{mm}}=-\mathrm{A} / \mathrm{T}+\mathrm{B}
$$

From plots of the logarithm of the equilibrium pressure against reciprocal temperature, various isopleths are obtained from which the constants, $A$ and $B$, can be calculated. Several representative isopleths are shown in Figure 2. Values of the constants and thermodynamic data for the various compositions are summarized in Table 2 . It is seen that there is a general increase in the heat of solution with hydrogen composition. 


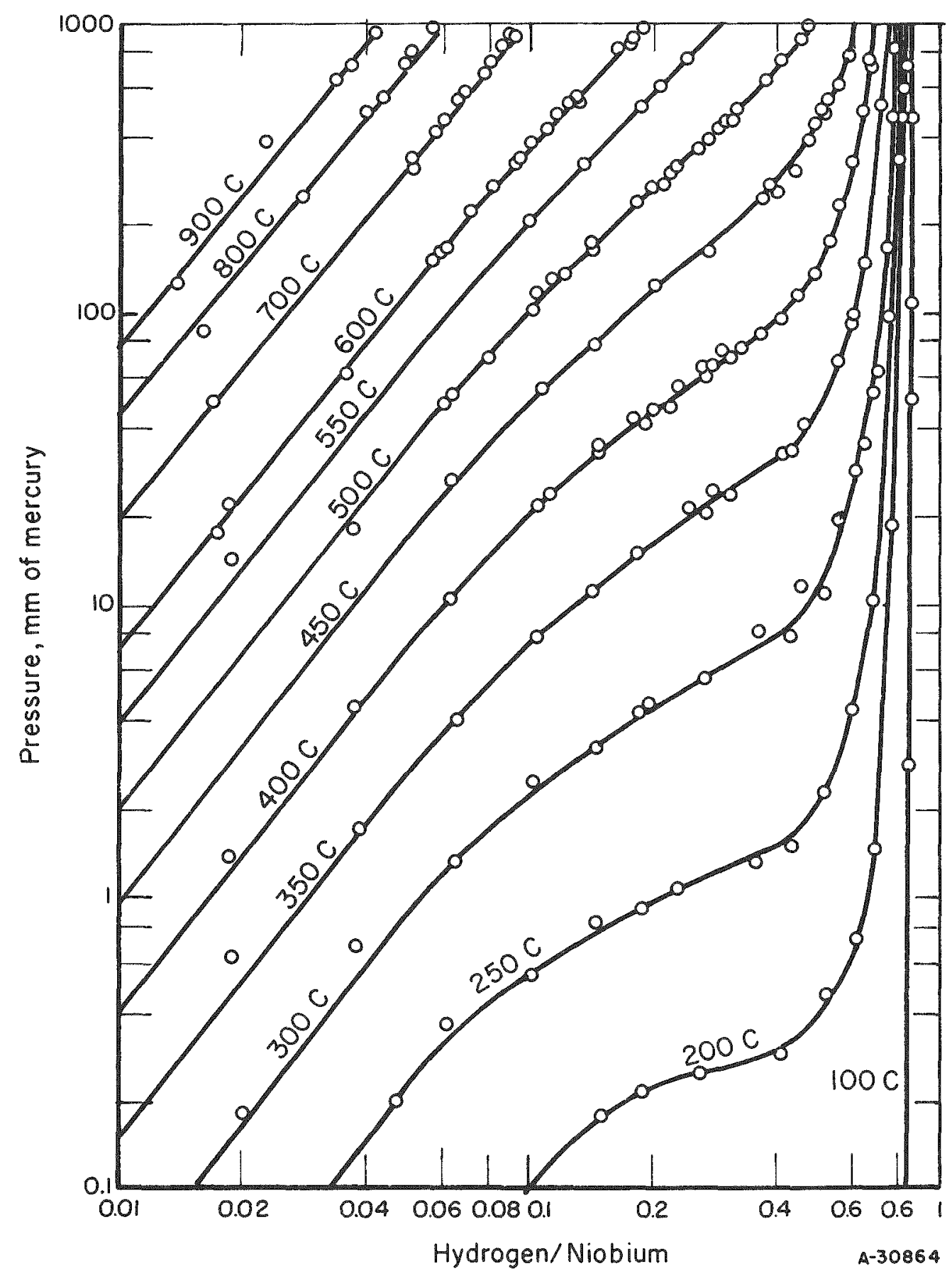

FIGURE 1. LOGARITHMIC PLOT OF ISOTHERMS IN THE NIOBIUM-HYDROGEN SYSTEM 


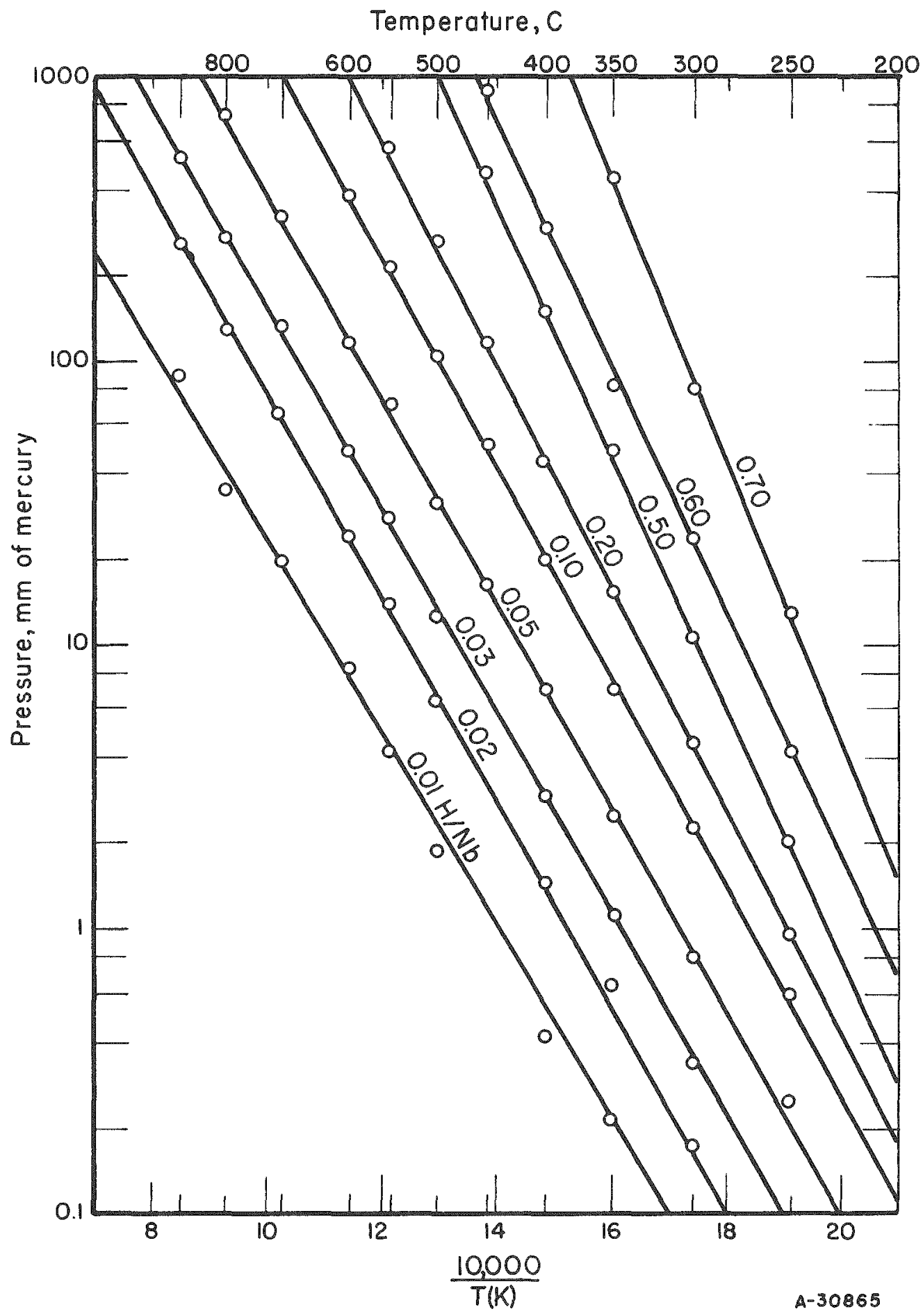

FIGURE 2. REPRESENTATIVE ISOPLETHS FOR THE NIOBIUM-HYDROGEN SYSTEM 
TABLE 2. THERMODYNAMIC DATA FOR VARIOUS NIOBIUM-HYDROGEN COMPOSITIONS

\begin{tabular}{|c|c|c|c|c|}
\hline \multirow{2}{*}{$\begin{array}{c}\text { Hydrogen/Niobium } \\
\text { Ratio }\end{array}$} & \multicolumn{2}{|c|}{$\begin{array}{c}\text { Constants in } \\
\log \mathrm{P} m \mathrm{~m}=-\mathrm{A} / \mathrm{T}+\mathrm{B}\end{array}$} & \multirow{2}{*}{$\begin{array}{c}\Delta H_{8} \\
\text { kcal per mole }\end{array}$} & \multirow{2}{*}{$\begin{array}{c}\Delta S_{8} \\
\operatorname{cal} /(m o l e)(K)\end{array}$} \\
\hline & $\mathrm{A}$ & $B$ & & \\
\hline 0.01 & 3478 & 4.833 & $15.90 \pm 0.20$ & $8.93 \pm 0.25$ \\
\hline 0.02 & 3592 & 5.490 & $16.40 \pm 0.13$ & $11.94 \pm 0.18$ \\
\hline 0.03 & 3567 & 5.770 & $16.33 \pm 0.07$ & $13.22 \pm 0.09$ \\
\hline 0.05 & 3575 & 6.170 & $16.40 \pm 0.11$ & $15.05 \pm 0.15$ \\
\hline 0.10 & 3688 & 6.801 & $16.90 \pm 0.12$ & $17.94 \pm 0.14$ \\
\hline 0.20 & 3953 & 7.548 & $18.09 \pm 0.04$ & $21.36 \pm 0.06$ \\
\hline 0.30 & 4149 & 8.030 & $18.99 \div 0.05$ & $23.57 \div 0.07$ \\
\hline 0.40 & 4301 & 8.403 & $19.70 \pm 0.12$ & $25.27 \pm 0.19$ \\
\hline 0.50 & 4424 & 8.765 & $20.20 \pm 0.14$ & $26.93 \pm 0.23$ \\
\hline 0.60 & 4319 & 8.895 & $19.80 \pm 0.29$ & $27.52 \pm 0.47$ \\
\hline 0.70 & 5005 & 10.670 & $22.90 \pm 0.71$ & $35.65 \pm 0.97$ \\
\hline
\end{tabular}

$\mathrm{X}$-ray diffraction measurements were made at room temperature to $400 \mathrm{C}$ on niobium and on specimens having $0.097,0.24$, and 0.54 hydrogen/niobium ratios. The data were obtained from $X$-ray patterns of the specimens contained in sealed quartz capillaries. In all cases body-centered-cubic structures were found. The variation of lattice parameters with temperature and composition are shown in Figure 3 . The specimens having hydrogen/niobium ratios of 0.097 and 0.54 contained two phases at room temperature and a single phase at $100 \mathrm{C}$ and above. The specimen having a 0.24 hydrogen/niobium ratio showed two phases at room temperature and $100 \mathrm{C}$ and one phase at $150 \mathrm{C}$ and above. In the single phases, the lattice parameters increased with temperature and with hydrogen content. From the data for niobium, the the rmalexpansion coefficient for the metal was calculated to be $7.9 \times 10-6$ per $C$. This is in good agreement with the handbook value of $7.1 \times 10^{-6}$ per C. (7) It can be seen in Figure 3 that the the rmal expansion of the specimens containing hydrogen is approximately the same as that of the metal. The change in lattice parameter with hydrogen concentration was calculated to be $0.0023 \pm 0.0002 \mathrm{~A}$ per a/o hydrogen.

The X-ray data in Figure 3 can be used to outline a two-phase region in the niobium-hydrogen system. The limits of the two-phase region were calculated to be at hydrogen/niobium ratios of 0.024 to 0.75 at room temperature and 0.099 to 0.52 at $100 \mathrm{C}$. Also, by extrapolating the equilibrium data to lower pressures, isobars of 0.01 and $0.001 \mathrm{~mm}$ of mercury were calculated which pass through the two-phase region. The phase diagram showing various isobars for the niobium-hydrogen system is presented in Figure 4. It is seen that the critical point where the two phases become identical is at about $140 \mathrm{C}, 0.01 \mathrm{~mm}$ of mercury hydrogen pressure, and 0.3 hydrogen/ niobium ratio. It should be noted that the designation of the high-hydrogen phase which was reported(1) previously as beta has been changed to alpha prime. This is in keeping with the customary nomenclature for solid solutions showing a miscibility gap.

Values for hydrogen solubility in niobium at pressure of 1 atm were recently reported by Paxton and Sheehan(2). Theix results are compared with those of Sieverts and Moritz(8) and of this study in Table 3. It is seen that solubilities of Paxton and Sheehan below $600 \mathrm{C}$ are considerably lower than those of the other studies. On the basis of the solubility study and high-temperature X-ray data, Paxton constructed a phase diagram for the niobium-hydrogen system showing the presence of the hydrides $\mathrm{Nb}_{2} \mathrm{H}$, having a hexagonal structure, and $\mathrm{NbH}$, having a body-centered-cubic structure. The presence of the hydride $\mathrm{Nb}_{2} \mathrm{H}$ is not indicated in the present study. Such a 


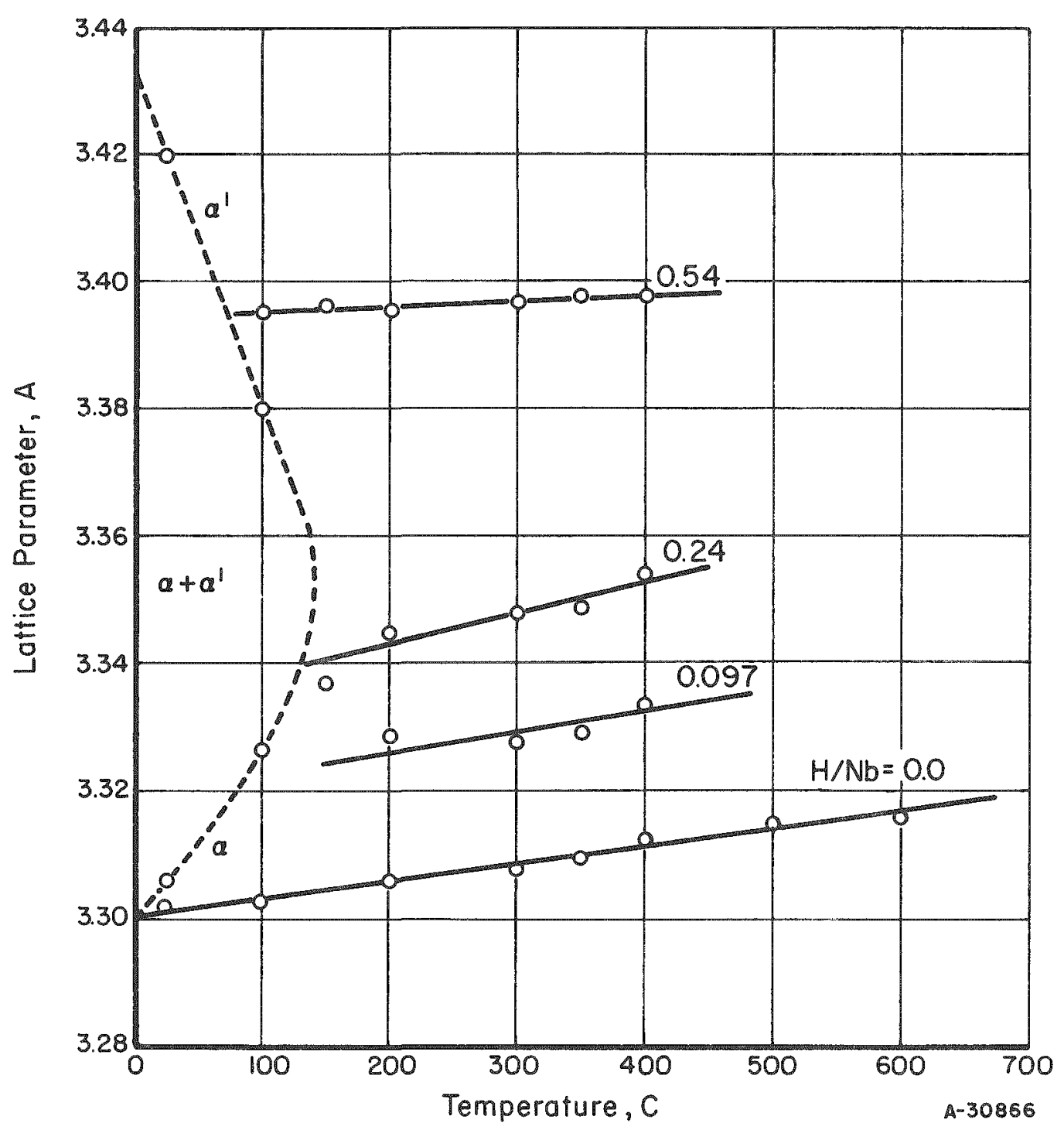

FIGURE 3. VARIATION OF LATTICE PARAMETER WITH TEMPERATURE AND COMPOSITION 


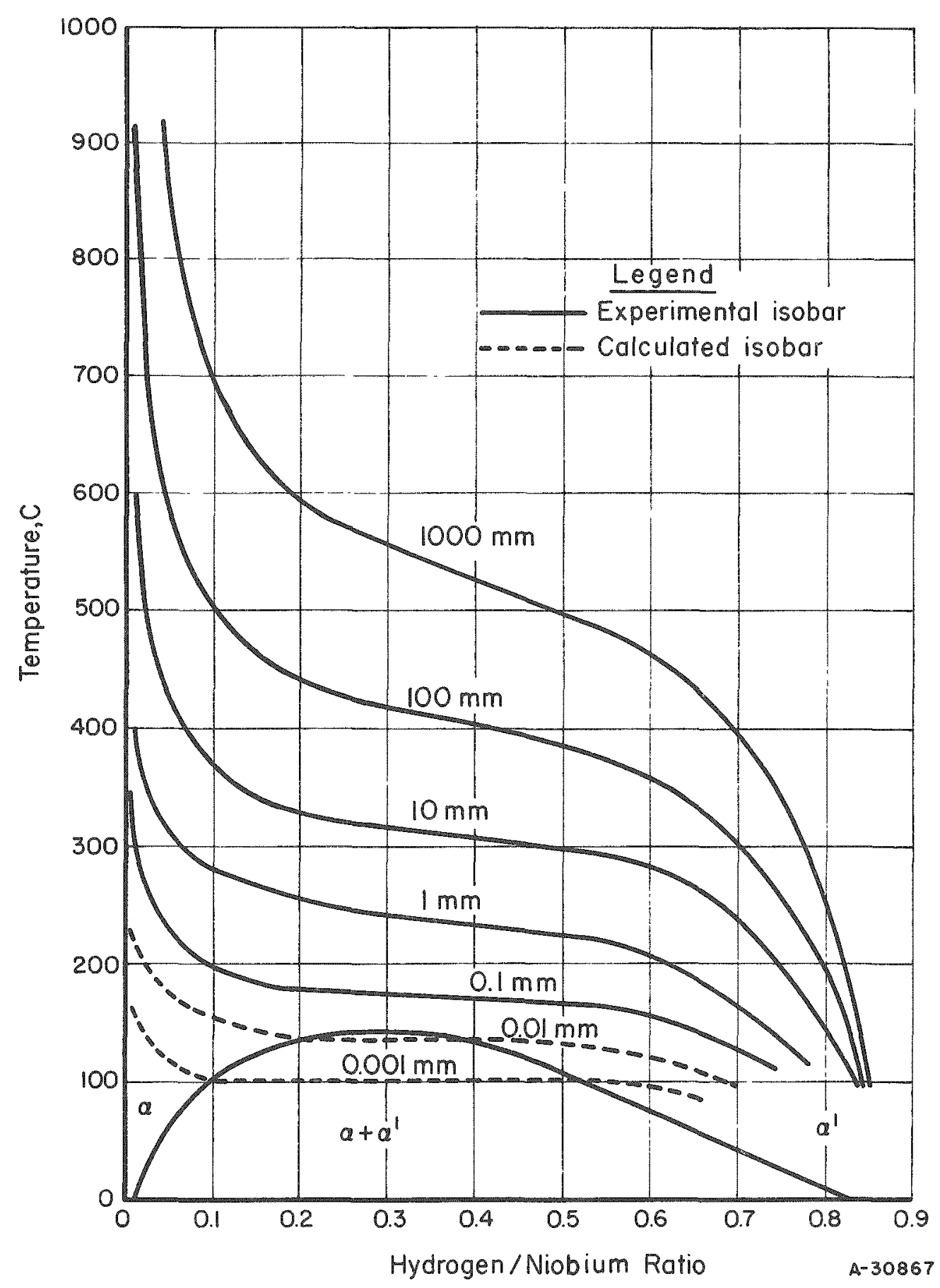

FIGURE 4. PHASE DIAGRAM OF THE NIOBIUM-HYDROGEN SYSTEM SIIOWING VARIOUS ISOBARS 
hexagonal structure has been attributed to impurities, probably nitrides, by Brauer and Hermann(9). The NbH structure of Paxton and Sheehan corresponds to the alpha prime structure of the present study.

TABLE 3. COMPARISON OF EQUILIBRIA DATA AT 1 ATM FOR THE NIOBIUM-HYDROGEN SYSTEM

\begin{tabular}{cccc}
\hline \hline \multirow{2}{*}{$\begin{array}{c}\text { Temperature, } \\
C\end{array}$} & \multicolumn{3}{c}{ Equilibrium Hydrogen/Niobium Ratio } \\
\cline { 2 - 4 } & Paxton and Sheehan & Sieverts and Moritz & Present Study \\
\hline 800 & 0.047 & 0.051 & 0.051 \\
600 & 0.16 & 0.15 & 0.16 \\
500 & 0.22 & 0.39 & 0.42 \\
400 & 0.55 & 0.64 & 0.68 \\
300 & 0.66 & 0.73 & 0.77 \\
\hline \hline
\end{tabular}

Sorption Kinetics and Diffusion

Kinetic data for the sorption of hydrogen by niobium to produce compositions with hydrogen/niobium ratios of $0.05,0.10,0.50$, and 0.70 were determined in the range 300 to $700 \mathrm{C}$. The experimental conditions of temperature and pressure were determined from the isopleth (Figure 2) of the desired product. Representative rate data are shown in Figures 5 and 6. For every reaction up to $550 \mathrm{C}$, the initial sorption rate was linear (see Figure 5). After a time, depending upon the conditions of the run, the rate decreased and the reaction stopped when equilibrium was established. Usually the reactions remained linear until about 40 to 50 per cent of saturation was attained. At 300 to $450 \mathrm{C}$ only the initial parts of the sorption curves were obtained because of the very long times to reach equilibrium. At 600 to $700 \mathrm{C}$ no initial linear rate was noted (see Figure 6). A summary of all the linear rate constants obtained at 300 to $550 \mathrm{C}$ is given in Table 4. The variation of the initial linear rate constants with temperature for the various compositions are shown in an Arrhenius plot in Figure 7. Data for the equation

$$
k=A \exp (-Q / R T)
$$

for each composition are given in Table 5. It was found that at a given temperature the initial linear rate increased with increasing hydrogen content of the product. Also, the activation energies increased with the hydrogen/niobium ratio.

Gulbransen and Andrew(3) found no consistent rate type for the niobium-hydrogen reaction from 250 to $900 \mathrm{C}$ at pressures up to $50 \mathrm{~mm}$ of mercury. A linear reaction rate was reported only at $300 \mathrm{C}$ and $21 \mathrm{~mm}$ of mercury hydrogen pressure. At these conditions, a composition having a hydrogen/niobium ratio of 0.6 would be produced. The rate constant calculated from their data is $1.6 \times 10-4 \mathrm{ml} /\left(\mathrm{cm}^{2}\right)(\mathrm{sec})$. This rate constant is in line with the present work. However, at 700 and $900 \mathrm{C}$ Gulbransen and Andrew found rather low reaction rates. They show reactions continuing up to $2 \mathrm{hr}$ using 3.3-mil-thick $(0.008 \mathrm{~cm})$ specimens. In the present study, a specimen $0.6 \mathrm{~cm}$ in diameter attained equilibrium solubility in about 5 min at $700 \mathrm{C}$ (see Figure 6).

At 600 to $700 \mathrm{C}$ the sorption curves could be described by a diffusion equation in which sorption is initially pa rabolic. Modifying the derivation of Demarez, et al., (10) the solution of Fick's second law for diffusion in a finite cylinder can be expressed as 


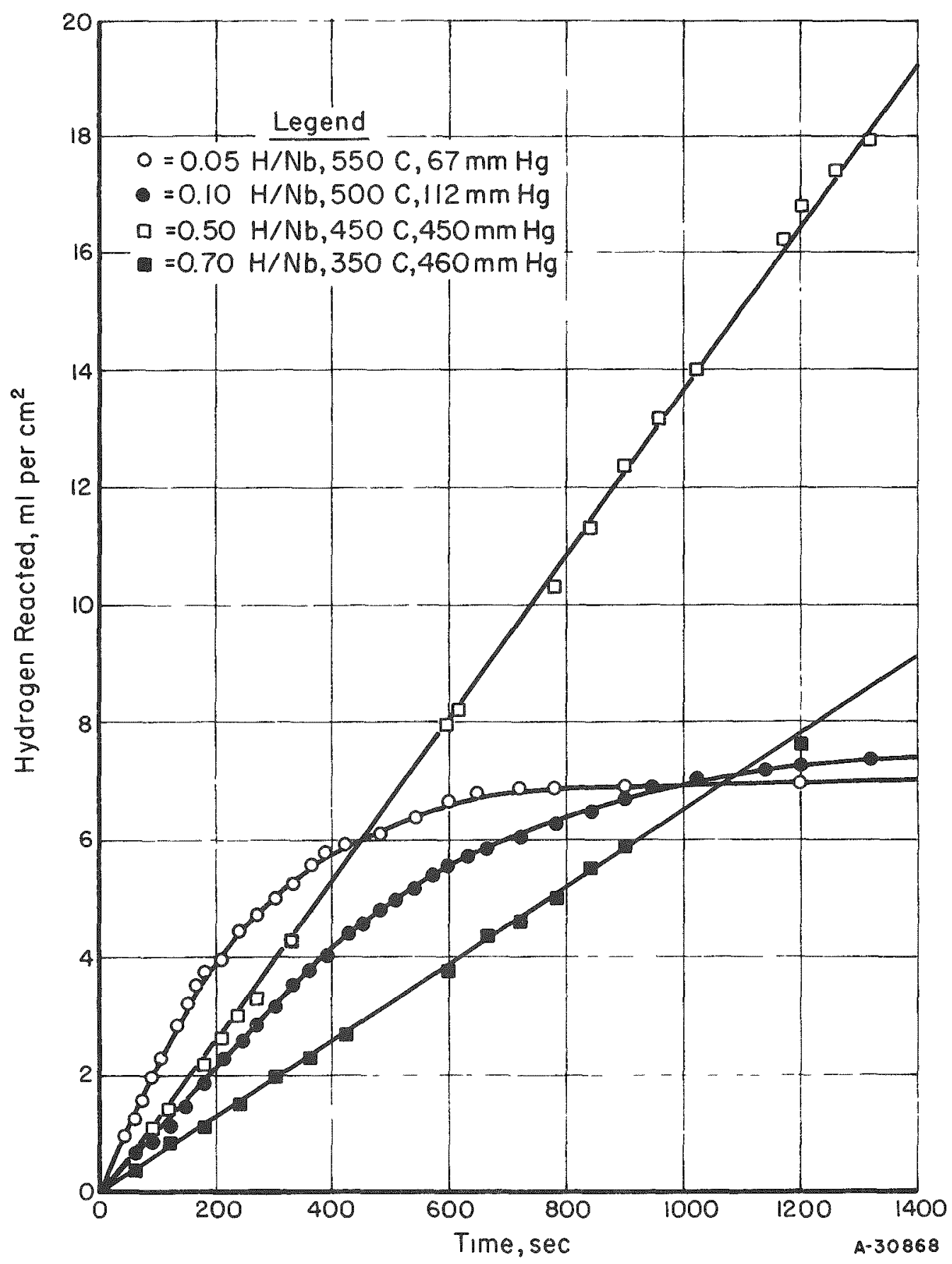

FIGURE 5. REPRESENT ATIVE RATE DATA FOR THE REACTION OF HYDROGEN WITH NIOBIUM 


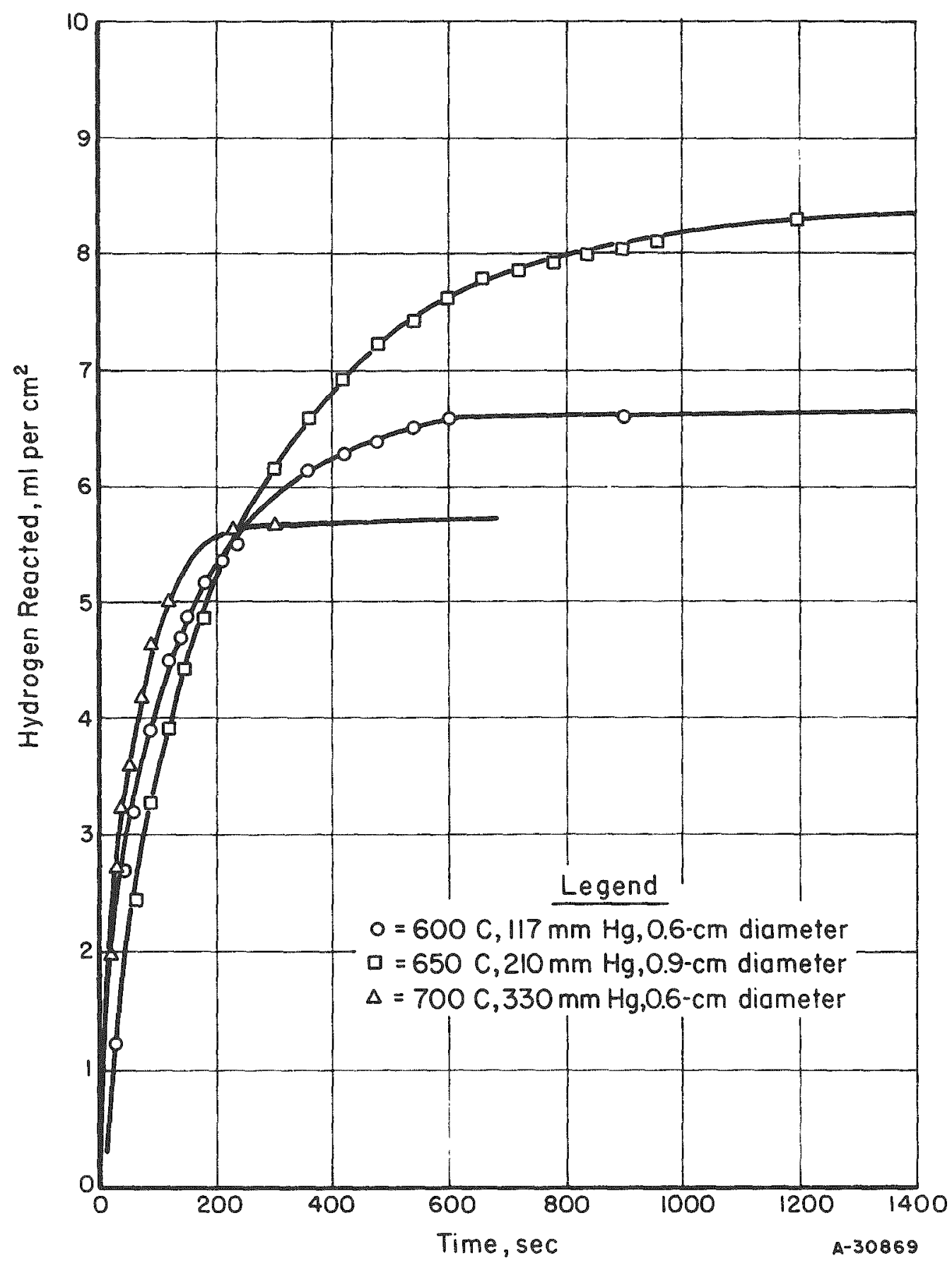

FIGURE 6. REPRESENTATIVE RATE DATA FOR REACTION OF HYDROGEN WITH NIOBIUM TO PRODUCE 0.05 HYDROGEN/NIOBIUM 
Temperature, $\mathrm{C}$

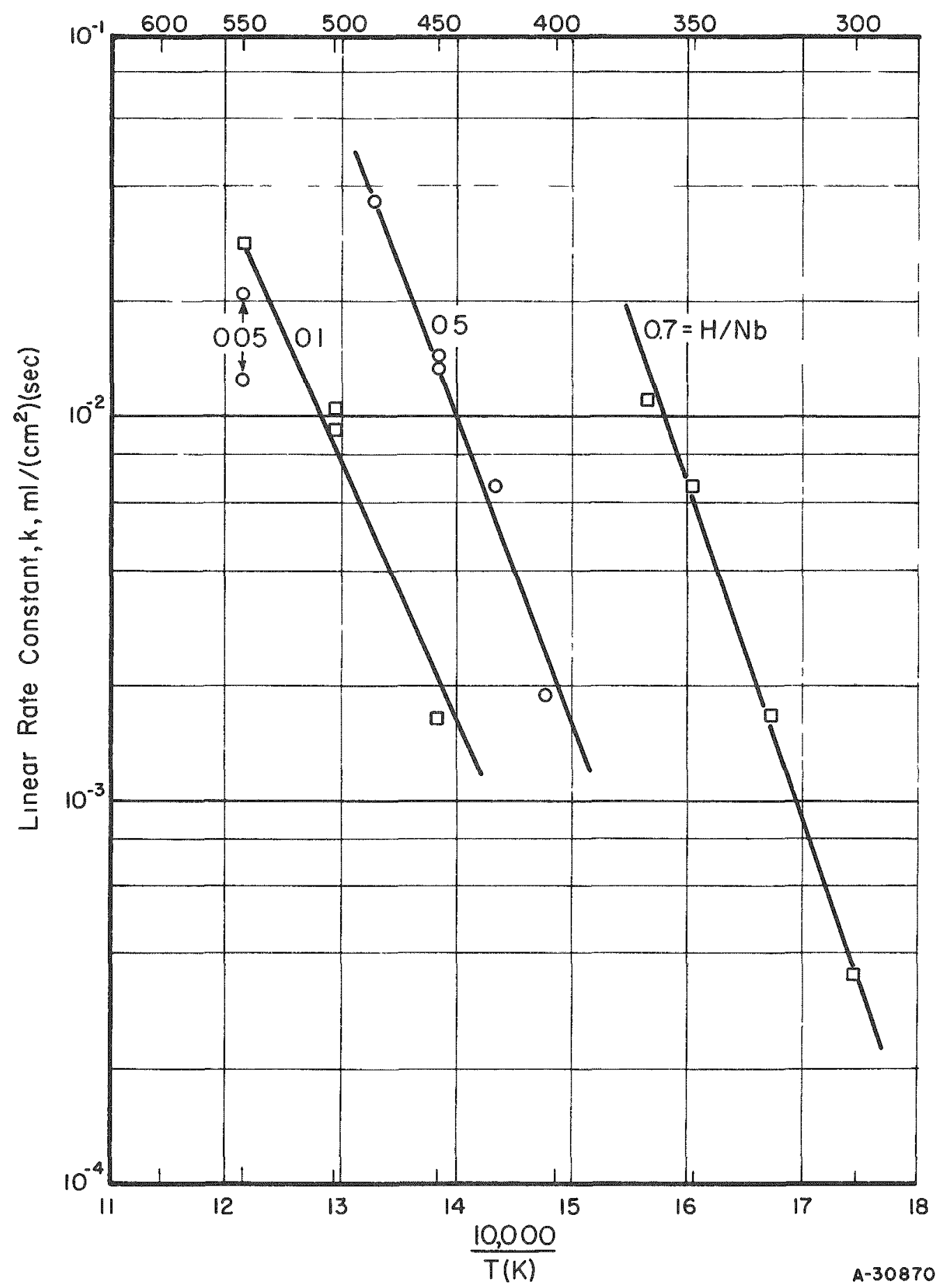

FIGURE 7. VARIATION OF LINEAR RATE CONSTANT WITH TEMPERATURE FOR SORPTION OF HYDROGEN IN NIOBIUM 
TABLE 4. SUMMARY OF INITIAL LINEAR RATE CONSTANTS FOR THE REACTION TO PRODUCE VARIOUS HYTROGEN-NIOBIUM COMPOSITIONS

\begin{tabular}{cccc}
\hline \hline $\begin{array}{c}\text { Hydrogen/Niobium } \\
\text { Ratio }\end{array}$ & $\begin{array}{c}\text { Temperature, } \\
\text { C }\end{array}$ & $\begin{array}{c}\text { Pressure, } \\
\text { mm of mercury }\end{array}$ & $\begin{array}{c}\text { Rate Constant, } \\
\left.10^{-3} \mathrm{~m} / / \mathrm{cm}^{2}\right)(\mathrm{sec})\end{array}$ \\
\hline 0.05 & 550 & 67 & 21 \\
& 550 & 69 & 12 \\
0.1 & & & \\
& 450 & 52 & 1.7 \\
& 500 & 112 & 9.1 \\
& 500 & 114 & 10 \\
0.5 & 550 & 218 & 29 \\
& 400 & & \\
& 425 & 145 & 1.9 \\
& 450 & 461 & 6.6 \\
& 450 & 480 & 14 \\
0.7 & 480 & 744 & 37 \\
& 300 & & \\
& 325 & 83 & 0.35 \\
& 350 & 210 & 1.7 \\
& 366 & 460 & 11 \\
\hline \hline
\end{tabular}

TABLE 5. RATE EQUATIONS FOR THE INITIAL LINEAR REACIION TO PRODUCE VARIOUS HYDROGEN SOLUTIONS

\begin{tabular}{|c|c|c|}
\hline \multirow[b]{2}{*}{$\begin{array}{l}\text { Hydrogen/Niobium } \\
\text { Ratio }\end{array}$} & \multicolumn{2}{|c|}{ Constants in the Arrhenius Equation } \\
\hline & Frequency Factor A & $\begin{array}{c}\text { Activation Energy, } \mathrm{Q} . \\
\text { kcal per C }\end{array}$ \\
\hline 0.10 & $1.32 \times 10^{7}$ & $32.6 \pm 1.0$ \\
\hline 0.50 & $1.39 \times 10^{9}$ & $36.4 \pm 1.3$ \\
\hline 0.70 & $2.18 \times 10^{11}$ & $38.7 \div 1.5$ \\
\hline
\end{tabular}




$$
C / C_{0}=1-\frac{32}{\pi^{2}} \sum_{n=0}^{\infty} \sum_{m=1}^{\infty} \frac{1}{\beta_{m}^{2}(2 n+1)^{2}} \exp \left\{-D t\left[\frac{(2 n+1)^{2} \pi^{2}}{l^{2}}+\frac{\beta_{m}^{2}}{a^{2}}\right]\right\},
$$

where

$$
\begin{aligned}
C & =\text { average hydrogen concentration at time, } t \\
C_{0} & =\text { final equilibrium hydrogen concentration } \\
\beta_{\mathrm{m}} & =a \text { root of the Bessel function, } J_{0}(\beta) \\
D & =\text { diffusion coefficient } \\
\ell & =\text { length of cylinder } \\
a & =\text { radius of cylinder. }
\end{aligned}
$$

The cylindrical specimens used in the sorption experiments had a length five times the radius $(l / a=5)$. Substituting 5 a for $l$, Equation (3) becomes

$$
C / C_{0}=1-\frac{32}{\pi^{2}} \sum_{n=0}^{\infty} \sum_{m=1}^{\infty} \frac{1}{\beta_{m}^{2}(2 n+1)^{2}} \exp \left\{-\left[\frac{(2 n+1)^{2} \pi^{2}}{25}+\beta_{m}^{2}\right] \frac{D t}{a^{2}}\right\} .
$$

The theoretical curve obtained from Equation $(4)$ is shown in Figure 8 , in which $\mathrm{C}_{\mathrm{O}} / \mathrm{C}_{\mathrm{O}}$ is plotted against $\left(\mathrm{Dt} / \mathrm{a}^{2}\right)^{1 / 2}$ so as to yield a straight line for the initial parabolic behavior. The parabolic rate is followed until about 40 per cent of saturation $\left(C / C_{O}=0.4\right)$ is attained. If the sorption of hydrogen is diffusion controlled, a proper choice of D would result in the experimental curves coinciding with the theoretical curve. The excellent agreement of several experimental curves at 600 , 650, and $700 \mathrm{C}$ with theory is also seen in Figure 8. It should be pointed out that the sorption curves obtained at the lower temperatures $(350$ to $550 \mathrm{C})$ did not follow the theoretical diffusion curve. Probably some surface reaction affected the sorption rates.

The diffusion coefficients that were calculated from sorption and desorption rate data are summarized in Table 6. It can be seen that the diffusion coefficients from the outgassing (desorption) experiments are somewhat lower than those obtained from sorption rates. There was a poor agreement of the desorption rates with diffusion theory so that diffusion coefficients calculated from desorption would be doubtful. The diffusion rates obtained from sorption data give the best values for the diffusion coefficients for hydrogen in niobium.

The diffusion coefficients reported by Paxton and Sheehan (2) and included in Table 6 are considerably lower than those of the present work. Paxton and Sheehan infer that a slow surface reaction in the permeation experiments may have affected their values of $D$. This is highly probable since they found that the niobium permeation membranes became discolored during their experiments. 


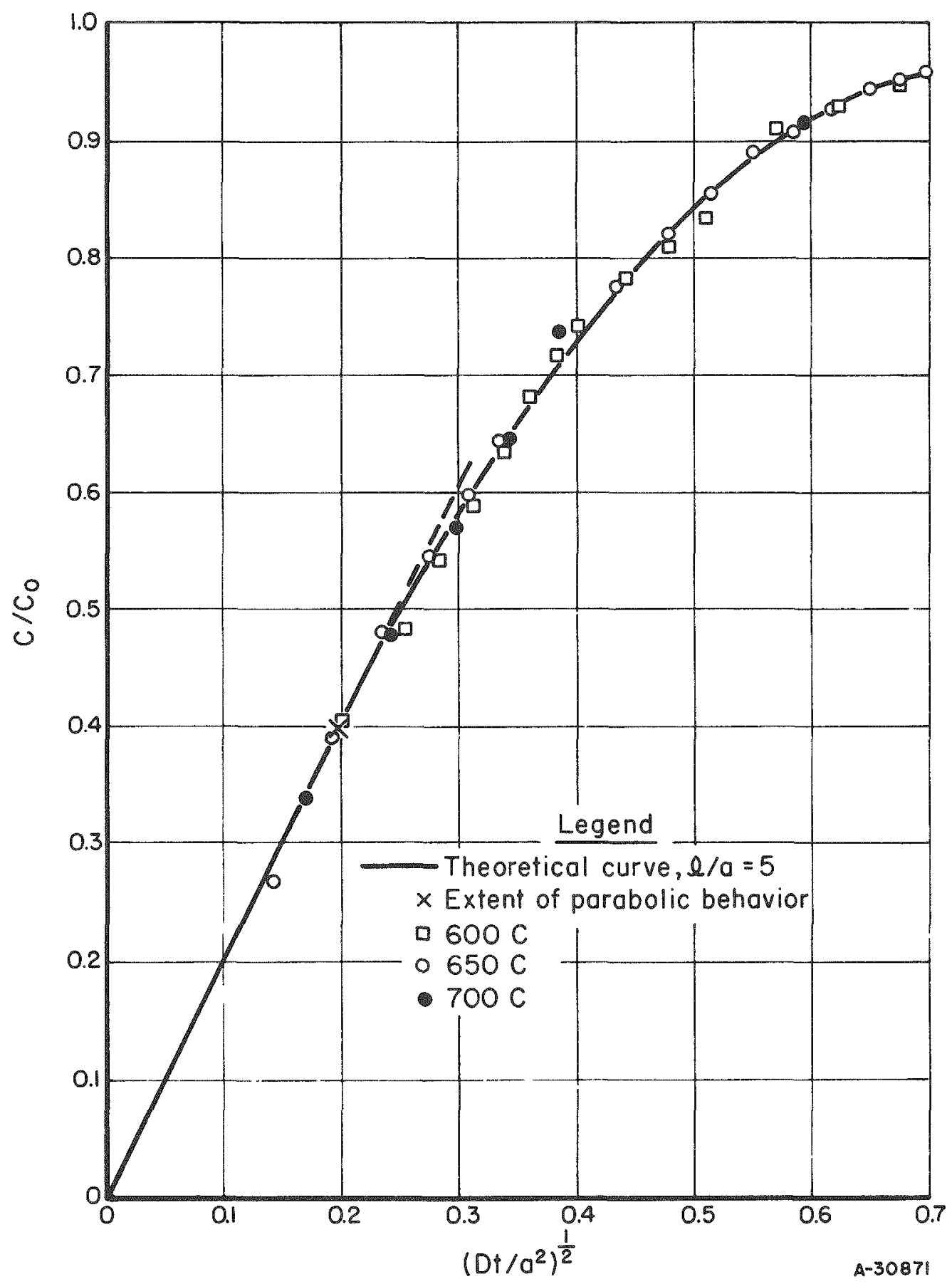

FIGURE 8. THEORETICAL AND EXPERIMENTAL DIFFUSION CURVES FOR SORPTION OF HYDROGEN IN NIOBIUM 
TABLE 6. DIFF USION COEFFICIENTS FOR THE NIOBIUM-HYDROGEN SYSTEM

\begin{tabular}{|c|c|c|c|}
\hline \multirow{3}{*}{$\begin{array}{c}\text { Temperature, } \\
\text { C }\end{array}$} & \multicolumn{3}{|c|}{ Diffusion Coefficient, $D, 10^{-5} \mathrm{~cm}^{2}$ per sec } \\
\hline & \multicolumn{2}{|c|}{ This Work } & \multirow[b]{2}{*}{ Paxton and Sheehan(a) } \\
\hline & From Sorption & From Desorption & \\
\hline 500 & $-\infty$ & 0.58 & 0.00011 \\
\hline 600 & 10 & 2.4 & 0.00063 \\
\hline 600 & 9.4 & $\infty$ & 0.001 \\
\hline 600 & 9.2 & $-\infty$ & $-\infty$ \\
\hline 650 & 14 & 4.3 & -- \\
\hline 650 & 13 & $\infty$ & $-\infty$ \\
\hline 700 & 16 & $-\infty$ & 0.0063 \\
\hline 700 & 18 & $\Rightarrow$ & 0.0036 \\
\hline
\end{tabular}

(a) From Reference (2).

The variation of the diffusion coefficient with temperature is described by the equation

$$
D=D_{0} \exp (-E / R T)
$$

The data obtained from sorption rates are shown in Figure 9. The equation for the best straight line through the points as determined by the method of least squares is

$$
D=0.0215 \exp [(-9370 \pm 600) / R T] \text {, }
$$

where $9370 \pm 600$ cal per $\mathrm{g}$-atom is the activation energy. The entropy of diffusion can be calculated from $D_{O}$ and $E$ using the theory of Wert and Zener $(11,12)$ for interstitial diffusion. For a body-centered-cubic lattice

$$
D_{0}=1 / 6 a_{0}^{2} \nu \exp (\Delta S / R)
$$

where $a_{0}$ is the lattice constant and $\nu$ is the frequency of vibration of a solute atom in an interstitial position. The vibration frequency can be approximated from the relationship,

$$
\nu=\left(E / 2 \mathrm{~m} \lambda^{2}\right)^{1 / 2}
$$

where $\mathrm{E}$ is approximately equal to the activation energy, $\mathrm{m}$ is the mass of the solute atom, and $\lambda$ is the distance between the interstitial positions $\left(\lambda=a_{0} / 2\right)$. From Equations (7) and (8), $\Delta S$ for diffusion of hydrogen in niobium was calculated to be $3.8 \mathrm{cal} /(\mathrm{g}$-atom $)(\mathrm{C})$. According to theory this low positive value of $\Delta S$ is characteristic of interstitial diffusion and not diffusion through grain boundaries or other shortcircuiting paths. 
Temperafure, $\mathrm{C}$

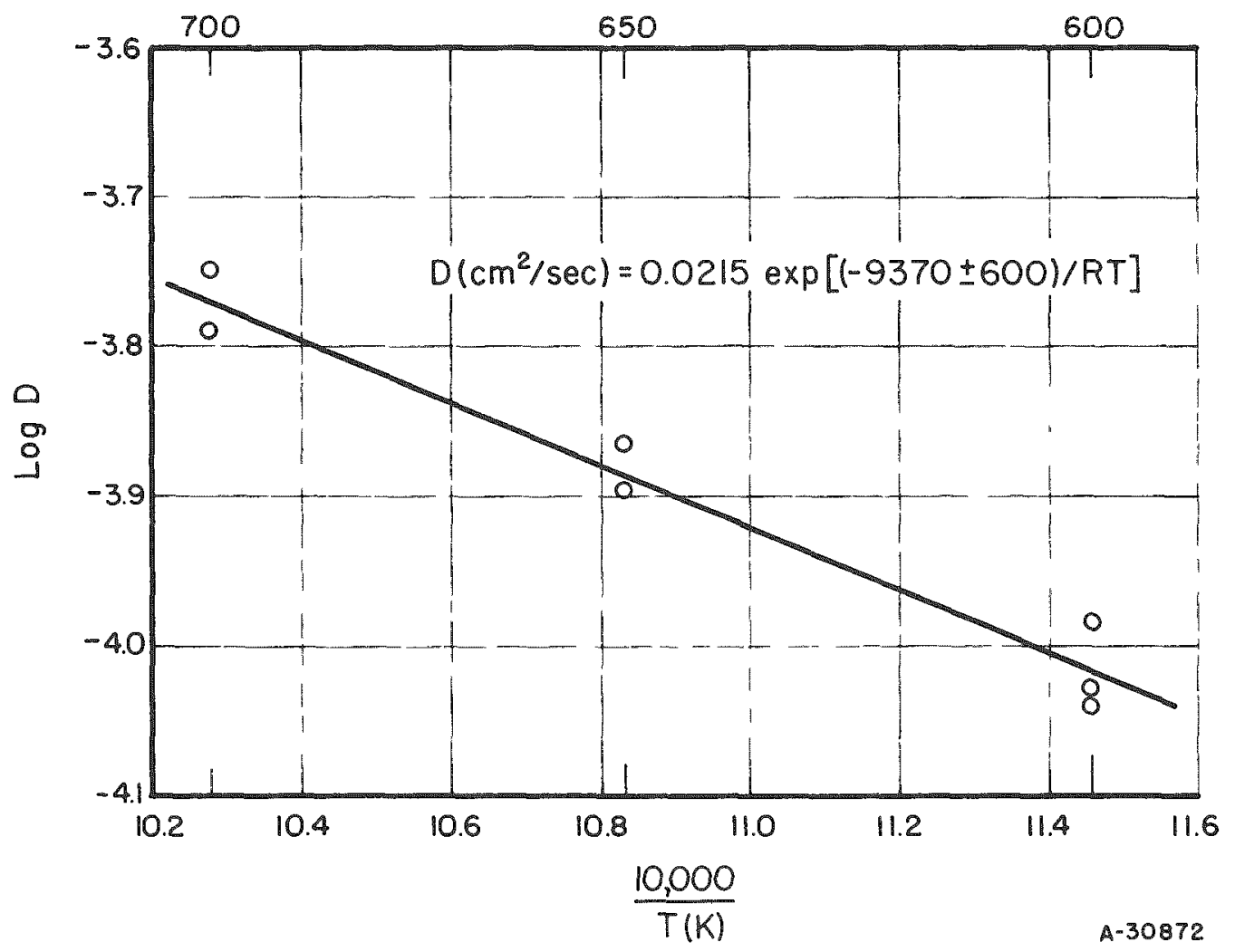

FIGURE 9. TEMPERATURE VARIATION OF DIFFUSION COEFFICIENTS FOR FIYDROGEN IN NIOBIUM 


\section{CONCLUSIONS}

The equilibria and $\mathrm{X}$-ray studies show that in the ranges 100 to $900 \mathrm{C}, 0.1$ to $1000 \mathrm{~mm}$ of mercury pressure, and 0.01 to 0.85 hydrogen/niobium ratios the niobium hydrogen system consists of a single-phase solid solution in which the basic bodycentered-cubic structure of the metal expands as the hydrogen concentration increases. Equilibria in the system are best described by a series of isopleths since the heat of solution increases with hydrogen content. A two-phase region showing a miscibility gap was found at relatively low temperatures and pressures. Calculations based on the equilibrium and $X$-ray data place the critical point where the two phases become identical at about $140 \mathrm{C}, 0.01 \mathrm{~mm}$ of me rcury hydrogen pressure, and 0.3 hydrogen/ niobium ratio. The two phases, alpha and alpha prime, are both body-centered-cubic structures differing only in lattice parameter and are considered to be solid solutions of hydrogen in niobium.

Rates were obtained for the sorption of hydrogen by niobium to produce several solid solutions having hydrogen/niobium ratios of $0.05,0.10,0.50$, and 0.70 . The initial rates determined from 300 to $550 \mathrm{C}$ were linear and increased with temperature and composition. At 600 to $700 \mathrm{C}$ sorption rates were diffusion controlled.

The diffusion coefficients obtained from desorption are lower than those obtained for sorption. Actually, the desorption curves show a poor agreement with diffusion theory. Apparently some surface reaction influences the desorption rate.

\section{ACKNOW LEDGMENT}

The authors wish to express their thanks to Mr. D. A. Vaughan of Battelle for making the many $\mathrm{X}$-ray measurements.

\section{REFERENCES}

(1) Albrecht, W. M., Mallett, M. W., and Goode, W. D., "Equilibria in the Niobium-Hydrogen System", J. Electrochem. Soc., 105, 219 (1958).

(2) Paxton, H. W., and Sheehan, J. M. " A Study of the Niobium-Hydrogen System", NYO-8040 (September, 1957).

(3) Gulbransen, A. E., and Andrew, K. F., "Kinetics of the Reactions of Columbium and Tantalum", Trans. AMME, 188, 586 (1950).

(4) Albrecht, W. M., and Mallett, M. W. "Reaction of Hydrogen With Uranium", J. Electrochem. Soc., 103, 404-9 (1956).

(5) Griffith, C.B., and Mallett, M. W., "Vacuum Metallurgy", Electrochemical Society, Inc., New York (1955), p 147. 
(6) Albrecht, W. M., and Mallett, M. W., "Hydrogen Solubility and Removal for Titanium and Titanium Alloys", Trans. AIME, 212, 204 (1958).

(7) Metals Handbook, American Society for Metals, Cleveland, Ohio (1948), p 20.

(8) Sieverts, A., and Moritz, H., Z. anorg. u. allegem. Chem., 247, 124 (1941).

(9) Brauer, G., and Hermann, R., Z. anorg. u. allegem. Chem., 274, 11 (1953).

(10) Demarez, A., Hock, A. J., and Meunier, F. A., "Diffusion of Hydrogen in Mild Stee1", Acta Met., 2, 214 (1954).

(11) Wert, C., and Zener, C., "Interstitial Atomic Diffusion Coefficients", Phys. Rev., 76, 1169 (1949).

(12) Zener, C., "Theory for Do for Atomic Diffusion in Metals", J. Appl. Phy., 22, 272. (1951).

WMA :WDG:MWM/mmk 